\title{
Dose effect of soy supplementation in prostate cancer: A pilot study
}

\author{
PETER J. VAN VELDHUIZEN ${ }^{1,2}$, J. BRANTLEY THRASHER ${ }^{1,3}$, GIBANANANDA RAY ${ }^{1,2}$, \\ RACHEL CHERIAN $^{1,4}$, JAN WARD ${ }^{1}$, JEFFREY HOLZBEIERLEIN ${ }^{1,3}$, \\ STEFAN GUTOW ${ }^{1,3}$ and SUSHANTA K. BANERJEE ${ }^{1,2}$ \\ ${ }^{1}$ Cancer Research Unit, Veteran Affairs Medical Center, and University of Kansas Medical Center; \\ ${ }^{2}$ Division of Oncology/Hematology, Department of Internal Medicine, Departments of \\ ${ }^{3}$ Urology and ${ }^{4}$ Pathology, University of Kansas Medical Center, Kansas City, Kansas, MO, USA
}

Received June 14, 2006; Accepted September 4, 2006

\begin{abstract}
We performed a pilot study to determine the dose effect of soy supplement on serum hormonal levels, estrogen receptor $\alpha(E R \alpha)$ and androgen receptor (AR) expression in patients scheduled to undergo prostatectomy. Cohorts of 3-4 eligible patients received escalating doses of a commercial soy supplement, Flav-ein, from the time of study enrollment until prostatectomy. Serum levels of prostate specific antigen (PSA), testosterone, and estrogen were measured at study enrollment and prior to prostatectomy. AR and ER $\alpha$ expression was evaluated in the pretreatment biopsy specimen and posttreatment prostatectomy specimen using immunohistochemical analysis. A total of 13 patients were enrolled in this pilot study and 11 patients were assessable for response. With soy supplementation, serum testosterone levels decreased in 9 of 11 patients and estrogen levels decreased in 8 of 10 patients in a dose-dependent manner. There was a variable effect on $\mathrm{ER} \alpha$ expression with downregulation of receptor expression seen at the highest dose level. There was no effect on AR expression. In conclusion, supplementation with this commercial soy product produced a consistent decrease in serum sex hormone levels. Additional studies are needed to evaluate a potential dose effect on ER $\alpha$ expression.
\end{abstract}

\section{Introduction}

Prostate cancer remains the most common malignancy in US males and is the second leading cause of malignancy related deaths. In the US, the incidence of this disease continues to increase as our population ages. It is estimated that 28,900

Correspondence to: Dr Peter J. Van Veldhuizen, Veteran Affairs Medical Center, 4801 Linwood Blvd., Kansas City, MO 64128, USA

E-mail: peter.vanveldhuizen@med.va.gov

Key words: soy supplements, isoflavones, prostate neoplasm, estrogen receptor deaths occurred secondary to prostate cancer in 2003 (1). Although prostate cancer has been predominantly considered to be a disease of older men, it can also occur in younger men. Sakr et al, demonstrated high grade prostatic intraepithelial neoplasia (PIN), a premalignant change which is felt to ultimately lead to the development of an invasive malignancy, in $5 \%$ of men in their 4 th decade of life, $10 \%$ of men in their 5 th decade of life and $63 \%$ of men in their 7 th decade of life. The corresponding figures for invasive carcinoma were 29, 32 and $64 \%$, respectively (2). The incidence of low grade PIN was $9 \%$ in men who were in only their third decade of life (3).

Clearly, factors that influence the development of PIN and the subsequent development of an invasive cancer occur early in life. Although the first premalignant changes occur at a young age, the majority of clinical cancers are not detected in most patients until after age 60 . This suggests that factors such as a lifetime exposure to a specific diet and/or specific serum androgen levels may not only be important to the ultimate promotion of tumor development but also ideal targets for tumor prevention $(4,5)$.

The preventive and the therapeutic effects of diet and nutrition on cancers including breast, colon and prostate cancer, have received significant attention $(6,7)$. As many as one-third of all cancer deaths in the US are thought to be linked to diet. Significant epidemiological evidence suggests a role of a variety of dietary factors including the degree of lycopene intake, consumption of red meats and the amount of dietary soy in prostate cancer (8-10). Studies conducted in Asian countries, where the average diet consists of 10 times the amount of soy products consumed compared to the average American diet, show that the incidence of prostate and breast cancer is significantly lower in these countries than in the US (11). Further supporting a dietary and environment influence is the finding that Asian immigrants who have moved to the US and develop a Western diet have a prostate cancer incidence that approaches US born males $(11,12)$. Despite the strong epidemiological data, the specific dietary factors effective in cancer prevention and the mechanism by which specific dietary interventions influence cancer development remains largely unknown. One hypothesis suggests that dietary micronutrients impact endogenous hormone levels, such as testosterone or 
dihydrotestosterone, and may represent an important factor in hormonally dependent cancers. Higher lifetime exposure to serum androgens may lead to an increased risk of developing a prostate carcinoma $(4,13,14)$.

The isoflavones, which are classified as phytoestrogens, are considered the responsible agents for the anticancer benefit of soy. Asian isoflavone intake is $\sim 50 \mathrm{mg} /$ day compared to the American intake of 2-3 mg/day (15). The most active anticarcinogen agent in soy is the isoflavone, genistein, and it has been targeted as a potential chemopreventative agent $(16,17)$. Other isoflavones such as daidzein, equol and biochanin A, also appear to modulate prostate cancer growth $(18,19)$. Additionally, experiments using animal model systems similarly demonstrate that soy isoflavones prevent or limit the growth and metastases of prostate tumors $(20,21)$.

Commercial soy products have been widely promoted and are consumed by a significant number of patients. The mechanism of action of these products, appropriate dose, degree of benefit and safety profile, remains largely unknown (22). Using a dose-escalation paradigm, we preformed a pilot study of a commercial soy product to further evaluate the effects of this supplement in prostate cancer patients.

\section{Patients and methods}

Study design. The overall design of this protocol was to treat patients who were scheduled to undergo radical prostatectomy for their prostate cancer with a commercial soy supplement. Cohorts of 3-4 patients received the supplement in a doseescalation fashion from the time of study enrollment until the time of prostatectomy. Serum levels of prostate specific antigen (PSA), total estrogen, DHEA, and testosterone were measured at the time of study enrollment and just prior to surgical resection. Paraffin slides were obtained from pretreatment biopsy specimens and the post-treatment prostatectomy specimens. Using immunohistochemistry, pre- and post-soy supplement sections were assessed for expression of estrogen receptor $\alpha(E R \alpha)$ and the androgen receptor (AR). Specimens were graded on a scale of $0-3+$ with zero being no expression and $3+$ being intense expression. In addition, all patients were monitored for toxicity.

Eligibility. All patients had histologically proven adenocarcinoma of the prostate and were candidates for radical prostatectomy. Patients were maintained on the supplement for at least 14 days prior to their surgery. All pre-study laboratory measurements were assessed within 14 days prior to registration and drawn in the early morning. During the study period, patients agreed not to take any new vitamin supplementations or herbal remedies. Patients were excluded if they were to receive concurrent chemotherapy, radiation or hormonal therapy and if they had taken any soy supplementation or soy isoflavones within 90 days prior to study enrollment. All patients signed an informed consent prior to study enrollment as approved by our institutional IRB/ Human subjects committee.

Supplementation with soy isoflavones. The first two patients received two servings daily of a commercial soy protein powder (Ultra-Soy, Genisoy Products Co., Fairfield, CA). A
Table I. PSA and testosterone with soy supplementation.

\begin{tabular}{lccccc}
\hline Patient $^{\mathrm{a}}$ & $\begin{array}{c}\text { Dose } \\
\text { level }\end{array}$ & $\begin{array}{c}\text { PSA } \\
\text { (pre) }\end{array}$ & $\begin{array}{c}\text { PSA } \\
\text { (post) }\end{array}$ & $\begin{array}{c}\text { Testosterone } \\
\text { (pre) }\end{array}$ & $\begin{array}{c}\text { Testosterone } \\
\text { (post) }\end{array}$ \\
\hline 1 & 1 & 14.4 & 5.2 & 4.48 & 4.22 \\
2 & 1 & 7.01 & 6.78 & 5.69 & 4.6 \\
3 & 1 & 3.77 & 3.15 & 1.48 & 1.67 \\
4 & 1 & 9.55 & 9.85 & 5.55 & 2.09 \\
5 & 2 & 6.64 & 6.8 & 4.43 & 5.88 \\
6 & 2 & 2.8 & 4.06 & 6.62 & 2.54 \\
7 & 2 & 6.13 & 4.29 & N/A & 1.73 \\
8 & 3 & 20.2 & 20.3 & 3.37 & 2.18 \\
9 & 3 & 9.4 & 9.9 & 7.13 & 4.28 \\
10 & 3 & 11.1 & 47.7 & 3.26 & 2.92 \\
11 & 3 & 1.38 & 2.11 & 2.26 & 1.37 \\
\hline
\end{tabular}

aPatients 1-4 received the equivalent of $112 \mathrm{mg}$ of daily isoflavones, patients 5-7 received $168 \mathrm{mg}$ of daily isoflavones and patients 8-11 received $224 \mathrm{mg}$ of daily isoflavones. Both PSA and testosterone levels are $\mathrm{ng} / \mathrm{ml}$.

manufacturing reformulation resulted in a product no longer consisting of pure soy and included several additional vitamin supplements. The protocol was subsequently amended and all remaining patients received Flav-ein capsules (3 B'S Ltd, Lenexa, KS). This supplement was chosen because it is an allnatural pure soy product and is in capsular form. Each capsule contains $560 \mathrm{mg}$ of soy extract and $100 \mathrm{mg}$ of legume powder with no additional additives. Each capsule contains $\sim 28 \mathrm{mg}$ of total isoflavones (10-20\% genistein, $50-70 \%$ daidzein, 20-40\% glycitein). To minimize variation in isoflavone content that can occur from harvest to harvest, the product was purchased in bulk. Three cohorts of patients received supplementation at the following three dose levels: 1) $112 \mathrm{mg}$ total isoflavones (two capsules twice daily), 2) $168 \mathrm{mg}$ total isoflavones (three capsules twice daily) and 3) $224 \mathrm{mg}$ total isoflavones (four capsules twice daily). Dose level 1 was equivalent to the isoflavone dose of the initial two patients who received the powdered supplement.

\section{Results}

Thirteen patients were enrolled over a six-month period. Eleven patients have completed treatment and undergone radical prostatectomy. One patient subsequently declined surgery and one was enrolled but later, because of a pre-existing cardiac condition, was subsequently considered not to be a surgical candidate. Of the 11 evaluable patients, 4 patients received dose level 1, 3 patients received dose level 2 , and 4 patients received dose level 3 . There were no thrombotic events or other toxicity seen in this trial. The median time on supplementation prior to prostatectomy was 28 days (range 16-76).

Table I shows pre- and post-soy PSA and testosterone values. The soy supplementation produced no consistent effect on serum PSA levels. There was an overall decrease in the serum testosterone level with a mean pre-soy level of $5.004 \mathrm{ng} / \mathrm{ml}$ compared to a post-soy level of $3.175 \mathrm{ng} / \mathrm{ml}$. All 
Table II. Estrogen levels with soy supplementation.

\begin{tabular}{ccccl}
\hline Patient & $\begin{array}{c}\text { Dose } \\
\text { level }\end{array}$ & $\begin{array}{c}\text { Estrogen } \\
\text { (pre) }\end{array}$ & $\begin{array}{c}\text { Estrogen } \\
\text { (post) }\end{array}$ & ER Receptor \\
\hline 1 & 1 & 182 & 150 & Increase \\
2 & 1 & 169 & 175 & No change \\
3 & 1 & 132 & 108 & Increase \\
4 & 1 & 129 & 156 & No change \\
5 & 2 & 205 & 158 & Increase \\
6 & 2 & 240 & 137 & Increase \\
7 & 2 & 166 & N/A & Increase \\
8 & 2 & 153 & 152 & No change \\
9 & 3 & 185 & 110 & Decrease \\
10 & 3 & 148 & 131 & No change \\
11 & 3 & 168 & 118 & Decrease \\
\hline
\end{tabular}

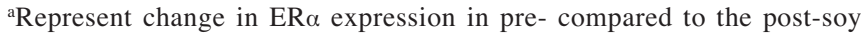
sample. Estrogen levels are $\mathrm{pg} / \mathrm{ml}$.

but 2 patients had a decreased testosterone level with supplementation, one in a patient receiving dose level 1 and one in a patient receiving dose level 2 . The mean decrease in the serum level was $1.15 \mathrm{ng} / \mathrm{ml}$ in dose level 1 compared to $1.36 \mathrm{ng} / \mathrm{ml}$ in dose level 3.

Table II lists the pre- and post-soy estrogen values. Levels of total estrogens decreased in 8 of the 10 evaluable patients and in all dose level 3 patients. The mean pre-soy total estrogen level was $171.1 \mathrm{pg} / \mathrm{ml}$ compared to $139.8 \mathrm{pg} / \mathrm{ml}$ post-soy. $\mathrm{ER} \alpha$ immunostained positively in 8 of the 11 pretreatment samples and in all post-treatment specimens. The remaining three patients (patients 1,6, and 7), exhibited only minimal cytoplasmic staining in the pretreatment sample, but significant expression post-treatment (Fig. 1). In two additional dose level 1 and 2 patients, there was a $1+$ increase in the intensity of ER $\alpha$ expression in the post-treatment specimen. In 2 of 4 patients treated with the highest dose of supplement (dose level 3), there was a clear decrease in ER $\alpha$ expression. In the 2 patients who had an increase in total estrogen levels with supplementation, there was no change in ER $\alpha$ expression. The ER $\alpha$ staining pattern was predominantly nuclear with variable cytoplasmic staining. Expression was equally present in both malignant and adjacent benign glands. AR expression did not change in the pre- and post-soy specimens with all samples intensely positive in both pre- and post-soy samples.

\section{Discussion}

The isoflavones are heterocyclic phenols with close structural homology to estrogens. Individually, isoflavones have weak estrogenic activity, possessing between $1 / 1,000$ and 1/100,000 the activity of synthetic estrogens (8). Agents that effect estrogen receptor expression may have a role in prostate cancer development and recent studies have suggested that certain polymorphisms in ER $\alpha$ are associated with an increased prostate cancer risk $(23,24)$. However, despite progress in defining the role of ER expression in prostate cancer $(25,26)$,
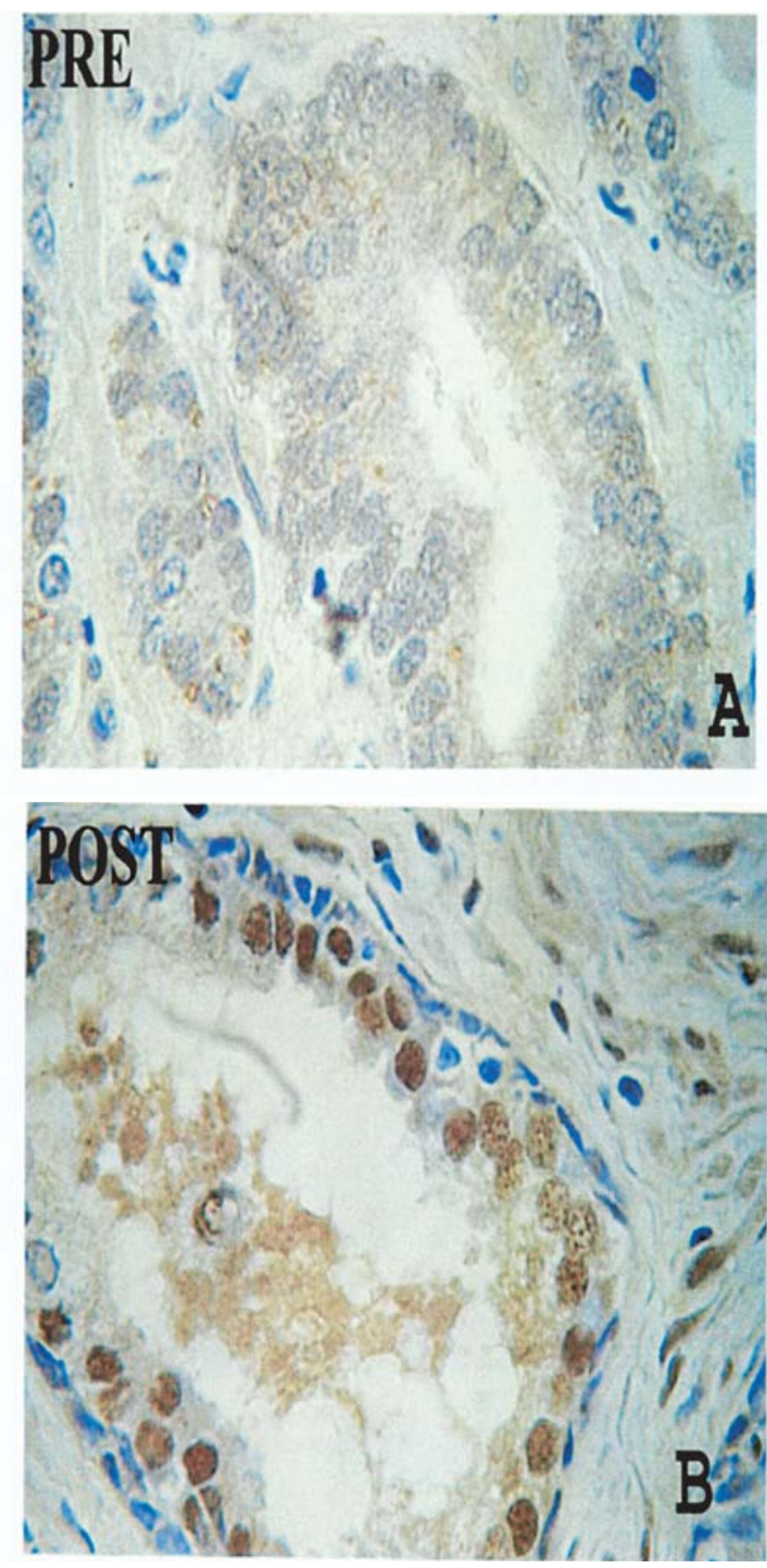

Figure 1. Estrogen receptor $\alpha(E R \alpha)$ expression in a prostate carcinoma from a patient treated with soy supplementation. (A) Untreated: there is minimal cytoplasmic staining and (B) Post-treatment: there is intense nuclear staining. Sections have been counterstained with hematoxylin.

the full clinical impact and the prognostic role of estrogen receptor expression in prostate cancer is still unknown.

Two animal studies have evaluated the effects of dietary genistein on estrogen receptor expression in the rat prostate. In the first study, animals receiving a continuous diet of genistein demonstrated downregulation of ERß but not ER $\alpha$ (27). A second study, noted significant dose-dependent downregulation of $\mathrm{ER} \alpha, \mathrm{ER} \beta$ and the androgen receptor in male Sprague-Dawley rats receiving dietary genistein (28).

In our study, we found a variable response in estrogen receptor expression. Of the 4 patients who received the highest dose level, 2 had a clear downregulation of receptor expression while expression increased in the lower dose patients. Three of the lower dose patients with increased 
expression had minimal cytoplasmic expression in the prestudy needle biopsy but 2-3+ expression in the post-soy radical prostatectomy specimen. Although ER expression occurred throughout the visualized gland in most positive specimens, potentially this could be related to a sampling error comparing the limited pre-study biopsy to the prostatectomy specimen.

Serum estrogen levels decreased with supplementation in 8 of 10 patients and testosterone levels decreased in 9 of 11 patients with a decrease occurring in all higher dose patients. A study evaluating the effect of soymilk on serum estrogen and androgen concentration found a similar decrease in serum estrone levels but not serum androgen levels (29). Whether the long-term benefit of a soy supplement is related to a positive effect on serum hormonal levels or by modulation of estrogen receptor status needs continued evaluation in larger clinical trials. Although treatment with an estrogenic agent could have potential toxicities such as increased thrombotic risk, no toxicity was seen with this supplement.

In conclusion, the findings in this pilot study suggest that the soy supplement, Flav-ein, decreases serum estrogen and testosterone levels in a majority of patients. In addition, there is a variable dose effect on ER $\alpha$ expression with downregulation of the receptor at higher supplementation levels but no effect on AR expression. Additional studies which also include measurement of tissue mRNA and a correlation with $\mathrm{ER} \alpha$ polymorphisms are needed to further investigate the significance of this dose effect.

\section{Acknowledgements}

This current study is the result of work supported by resources and the use of facilities at the Kansas City Veterans Affairs Medical Center (Kansas City, MO) and a generous gift from the Ladies Auxiliary VFW Department of Missouri.

\section{References}

1. Jemal A, Thomas A, Murray T, et al: Cancer Statistics, 2003. CA Cancer J Clin 53: 5-26, 2003.

2. Sakr WA, Grignon DJ, Crissman JD, et al: High grade prostatic intraepithelial neoplasia (HGPIN) and prostatic adenocarcinoma between the ages of 20-69: an autopsy study of 249 cases. In Vivo 8: 439-443, 1994

3. Sakr WA, Haas GP, Cassin BF, et al: The frequency of carcinoma and intraepithelial neoplasia of the prostate in young male patients. J Urol 150: 379-385, 1993.

4. Debes JD and Tindall DJ: The role of androgens and the androgen receptor in prostate cancer. Cancer Lett 10: 1-7, 2002.

5. Adlercreutz H and Mazur W: Phyto-oestrogens and Western diseases. Ann Med 29: 95-120, 1997.

6. Shirai T, Asamoto M, Takahashi S and Imaida K: Diet and prostate cancer. Toxicology 27: 89-94, 2002.

7. Cassidy A: Potential risks and benefits of phytoestrogen-rich diets. Int J Vitam Nutr Res 73: 120-126, 2003.

8. Hadley CW, Miller EC, Schwartz SJ and Clinton SK: Tomatoes, lycopene, and prostate cancer: progress and promise. Exp Biol Med 227: 869-880, 2002.
9. Ferguson LR: Meat consumption, cancer risk and population groups within New Zealand. Mutat Res 30: 215-224, 2002.

10. Messina MJ: Legumes and soybeans: overview of their nutritional profiles and health effects. Am J Clin Nutr 70 (Suppl 3): S439-S450, 1999.

11. Muir CS, Nectoux J and Staszewski J: The epidemiology of prostate cancer: geographical distribution and time trends. Acta Oncol 30: 1333-1340, 1991.

12. Shimizu H, Ross RK, Bernstein, et al: Cancers of the prostate and breast among Japanese and white immigrants in Los Angeles County. Br J Cancer 63: 963-966, 1991.

13. Moyad MA: Lifestyle/dietary supplement partial androgen suppression and/or estrogen manipulation. A novel PSA reducer and preventive/treatment option for prostate cancer? Urol Clin North Am 29: 115-124, 2002.

14. Rao GN: Influence of diet on tumors of hormonal tissues. Prog Clin Biol Res 394: 41-56, 1996.

15. Mazur W: Phytoestrogen content in foods. Baillieres Clin Endocrinol Metab 12: 729-742, 1998.

16. Lamartiniere CA, Cotroneo MS, Fritz WA, et al: Genistein chemoprevention: timing and mechanisms of action in murine mammary and prostate. J Nutr 132: S552-S558, 2002.

17. Sarkar FH and Li Y: Mechanisms of cancer chemoprevention by soy isoflavone genistein. Cancer Metastasis Rev 21: 265-280, 2002 .

18. Rice L, Samedi VG, Medrano TA, Sweeney CA, Baker HV, Stenstrom A, Furman J and Shiverick KT: Mechanisms of the growth inhibitory effects of the isoflavonoid biochanin A on LNCaP cells and xenografts. Prostate 52: 201-212, 2002.

19. Hedlund TE, Johannes WU and Miller GJ: Soy isoflavonoid equol modulates the growth of benign and malignant prostatic epithelial cells in vitro. Prostate 54: 68-78, 2003.

20. Pollard M, Wolter W and Sun L: Prevention of induced prostaterelated cancer by soy protein isolate/isoflavone-supplemented diet in Lobund-Wistar rats. In Vivo 14: 389-392, 2000.

21. Zhou JR, Yu L, Zhong Y, Nassr RL, Franke AA, Gaston SM and Blackburn GL: Inhibition of orthotopic growth and metastasis of androgen-sensitive human prostate tumors in mice by bioactive soybean components. Prostate 53: 143-153, 2002.

22. Golwyn S, Lazinsky A and Wei H: Promotion of health by soy isoflavones: efficacy, benefit and safety concerns. Drug Metabol Drug Interact 17: 261-289, 2000.

23. Suzuki K, Nakazato H, Matsui H, et al: Genetic polymorphisms of estrogen receptor alpha, CYP19, catechol-O-methyltransferase are associated with familial prostate cancer risk in a Japanese population. Cancer 98: 1411-1416, 2003.

24. Cancel-Tassin G, Latil A, Rousseau F, et al: Association study of polymorphisms in the human estrogen receptor alpha gene and prostate cancer risk. Eur Urol 44: 487-490, 2003.

25. Linja MJ, Savinainen KJ, Tammela TL, et al: Expression of ERalpha and ERbeta in prostate cancer. Prostate 55: 180-186, 2003.

26. Cunha GR, Wang YZ, Hayward SW and Risbridger GP: Estrogenic effects on prostatic differentiation and carcinogenesis. Reprod Fertil Dev 13: 285-296, 2001.

27. Dalu A, Blaydes BS, Bryant CW, et al: Estrogen receptor expression in the prostate of rats treated with dietary genistein. $\mathrm{J}$ Chromatogr B Analyt Technol Biomed Life Sci 777: 249-260, 2002.

28. Fritz WA, Wang J, Eltoum IE and Lamartiniere CA: Dietary genistein down-regulates androgen and estrogen receptor expression in the rat prostate. Mol Cell Endocrinol 186: 89-99, 2002.

29. Nagata C, Takatsuka N, Shimisu H, Hayashi H, Akamatsu T and Murase K: Effect of soymilk consumption on serum estrogen and androgen concentration in Japanese men. Cancer Epidemiol Biomarkers Prev 10: 170-184, 2001. 